\title{
What matters when prioritizing a medicinal plant? A study of local criteria for their differential use
}

\author{
Carina Silva Santos ${ }^{1}$, Fernanda Novais Barros ${ }^{2}$, Marcelo de Paula ${ }^{2}$, Juliana Rando ${ }^{2}$, Viviany Teixeira do \\ Nascimento ${ }^{1}$ and Patrícia Muniz de Medeiros ${ }^{3 *}$
}

Received: September 23, 2017

Accepted: January 2, 2018

\begin{abstract}
The ethnobotanical literature lacks joint analyses of the factors that may influence the differential use of medicinal plants. This study intends to fill that void by evaluating the local criteria for the differential use of medicinal plants in a rural community in Northeastern Brazil. We chose two health problems (influenza and constipation) characterized as diseases by local (emic) classification to address the following hypotheses: (1) the most important medicinal plants are easier to acquire; (2) the most important medicinal plants are perceived as being more efficient; and (3) the most important medicinal plants taste better (greater palatability). The plants mentioned in interviews were ranked according to the perception of their use (dependent variable), the difficulty of their acquisition, their taste and their efficiency (independent variables). The perceived efficiency explained the use of medicinal plants for both diseases, while taste explained the use only for constipation. The final models for 'influenza' contained only efficiency, while those for 'constipation' contained all three variables. These findings indicate that medicinal categories many not be homogeneous and that different targets may be influenced by different variables.
\end{abstract}

Keywords: differential use, evolutionary ethnobiology, human ecology, socio-ecological systems, traditional ecological knowledge

\section{Introduction}

In recent years, there has been an increasing trend in the use of ecological and evolutionary approaches in modern ethnobiology, especially in ethnobotany (see Albuquerque et al. 2015), and factors influencing human foraging behavior are among the main interests of scientists studying evolutionary ethnobiology. Recent studies have addressed local criteria involved in medicinal plant selection (Ankli et al. 1999; Omar et al. 2000; Gonçalves et al. 2016), which is a process that includes two phenomena, namely the introduction (entrance) of a particular species into a local medical system and the differential use of that species (Medeiros et al. 2015a).

Research conducted in relation to the first phenomenon is designed to determine the factors involved in a species being considered medicinal, and research into the second phenomenon is focused on the factors responsible for different degrees of popularity or prioritization of medicinal plant species (e.g., more frequently used species versus less frequently used species), the versatility of medicinal plant species (species used for several therapeutic indications versus species used for only a few indications), or different therapeutic indications attributed to medicinal plant species.

1 Universidade do Estado da Bahia, Campus IX, 47800-000, Barreiras, BA, Brazil

2 Centro das Ciências Biológicas e da Saúde, Universidade Federal do Oeste da Bahia, 47800-000, Barreiras, BA, Brazil

3 Centro de Ciências Agrárias, Universidade Federal de Alagoas, 57100-000, Rio Largo, AL, Brazil

*Corresponding author: patricia.medeiros@ceca.ufal.br 
Factors that may influence the introduction of medicinal plants and their differential utilization in a local medical system have been discussed in the literature as follows: plant availability (Lucena et al. 2007; 2012), chemical/therapeutic efficiency (Slish et al. 1999; Khafagi \& Dewedar 2000; Araújo et al. 2008), cultural perspectives (Rodrigues \& Carlini 2006; Mollik et al. 2010), and organoleptic properties (taste and smell) (Ankli et al. 1999; Leonti et al. 2002; Molares \& Ladio 2009; Medeiros et al. 2015b).

However, some gaps are still found in the literature, given that (1) such factors are often isolated in the analyses, so that we cannot observe their joint effects, and (2) they are commonly measured through conventional ecological and pharmacological indicators (e.g., vegetation parameters and chemical measurements) so that perceived indicators (e.g., perceived efficiency and availability) are often neglected.

Therefore, this study intends to fill one such gap by evaluating the local criteria for the differential use of medicinal plants in terms of prioritization. We chose two health problems locally considered to be diseases (influenza and constipation) to propose the following hypotheses: (1) the most important medicinal plants are easier to acquire, (2) the most important medicinal plants are perceived as more efficient, and (3) the most important medicinal plants taste better. We also developed models to identify the variables with stronger predictive power for the differential use of medicinal plants employed to treat influenza and constipation.

The health problems mentioned above are considered to be diseases according to an emic categorization. They were chosen because in the studied context they both require the plants' ingestion (allowing the evaluation of the role of plant's taste), and they are often associated with several cited species in ethnobotanical surveys (a high number of species is important for the consistency of the statistical analysis). However, we could also have chosen other diseases that would meet our requirements. We chose diseases that belonged to two different body systems (digestive and respiratory) because we wanted to observe whether diseases with different natures followed the same logic for the differential use of plants. They are also the body systems with more plant citations in several ethnobotanical studies developed in Brazil (Albuquerque et al. 2007).

\section{Materials and methods}

\section{Study area}

This study was carried out in the rural community of Canabrava, in the municipality of Barreiras, Bahia State, Northeastern Brazil. Canabrava is in the Brazilian cerrado, and it has seasonally dry tropical forests, savannas and riparian vegetation. The community is $13 \mathrm{~km}$ away from the municipality's urban area, and it was founded before
1885. It is composed of 59 inhabitants in 25 households. The main economic activity is small-scale agriculture, and agricultural crops are often sold in the Barreiras central market.

There are no health centers in the community, so the local dwellers have to go to the Barreiras urban area for medical consultations. The only basic school is no longer operative, and the local students usually frequent schools in the neighboring communities.

\section{Data collection}

This study is part of a project entitled Conhecimento, uso e representações locais sobre recursos vegetais em comunidades rurais das regiões central e oeste da Bahia: aspectos teóricos e implicações para a conservação (Knowledge, use and local representations of plant resources in rural communities of Central and Western Bahia: Theoretical aspects and implications for conservation), which was submitted to and accepted by the Ethics Committee of the Faculdade São Francisco de Barreiras (CAAE 44962515.5.0000.5026).

Semi-structured interviews were conducted in the first semester of 2015 with 35 local dwellers who were 18 years of age or older. Socioeconomic data were recorded, and the interviewees were asked to mention plants known to treat two targets (influenza and constipation). We only considered direct citations for the selected targets (e.g., we gave 'influenza' as a stimulus rather than cough, sneeze, etc.).

For each target, when the interviewee finished the list, he or she was invited to rank the cited species according to: (a) the frequency of use (from the most commonly used to the least commonly used for the target), (b) the perceived difficulty of acquisition (from the most difficult to obtain to the least difficult to obtain, as perceived by the interviewee), (c) the perceived taste (from the plants with more pleasant taste or higher palatability to the plants with less pleasant taste or lower palatability) and (d) the perceived efficiency (from the plant perceived as the most efficient to treat the target to the least efficient).

Rank attribution for 'the difficulty of acquisition' was performed regardless of the means of acquisition (collection, trade, etc.). As such an attribution considered the local perception, a traded species A could be considered more difficult to acquire than a collected species $B$, when people believed that the price of plant A overcame the energy spent in the collection of plant B.

The plant species mentioned by the interviewee were collected, identified and deposited in the herbarium of the Universidade Federal da Bahia (BRBA). Some species did not have specimens deposited in the herbarium, since they did not have reproductive parts when the collections were performed, or the interviewee did not provide us with material to be deposited in the herbarium. However, these 
were well-known species, and most of them were exotic plants with worldwide distributions. Therefore, our team could perform such identifications in the field.

\section{Data analysis}

For all variables (relative frequency of use, perceived availability, taste and perceived efficiency), we calculated average ranks for the cited species as follows:

$$
A R_{i}=\frac{\sum I R_{i}}{N_{i}}
$$

where $A R_{i}$ is the average rank of species $i, \mathrm{IR}_{i}$ is the individual rank of species $i$ (from 1 to the total number of plants cited by the interviewee for a given target) and $\mathrm{N}_{i}$ is the total number of people who cited species $i$.

We excluded from the calculation the species that were mentioned by only one interviewee to avoid the effect of idiosyncratic information.

To test the first hypothesis (the most important medicinal plants are easier to acquire), we performed a simple regression considering the mean rank for 'use' as the dependent variable (our measure of plant importance) and the mean rank for 'perceived difficulty of acquisition' as the independent variable.

The second hypothesis (the most important medicinal plants are perceived as more efficient) was tested by performing another simple regression with the mean rank for 'use' as the dependent variable and the mean rank for 'perceived efficiency' as the independent variable.

For the third hypothesis (the most important medicinal plants have better tastes), we also used a simple regression considering the mean rank for 'use' as the dependent variable and the mean rank for 'perceived taste' as the independent variable.

After the independent variables were individually tested, we performed a multiple regression with a stepwise approach to identify the variables that would remain in the final model (those that explained the medicinal plant use). This approach is necessary because sometimes two factors individually explain a dependent variable, but when there is a high degree of autocorrelation, only one of them is the true explanatory variable. Therefore, the final model of the multiple regression with the stepwise approach accounts for such situations.

For all analyses of the target 'constipation', the dependent variable (mean rank for 'use') was transformed (fourth root transformation) to achieve a normal distribution. The fourth root transformation was chosen because it led to a better adjustment to a normal distribution and better statistical adjustment than other types of transformation (e.g., square root and logarithmical).

Analyses were performed with R version 2.13.2 (The R Foundation for Statistical Computing).

\section{Results}

\section{Medicinal plants cited to treat influenza and constipation}

A total of 13 species were mentioned as being known to treat influenza by more than one interviewee (Tab. 1). The most cited species were Mentha spicata $(57.1 \%$ of the interviewees), Ocimum gratissium (48.6\%) and Mentha pulegium (42.9\%).

For constipation, the total number of species cited was also 13 (Tab. 1). The most commonly cited species were Amburana cearensis (42.9\%), Plectranthus amboinicus (20\%) and Lippia alba (17.1\%).

The most important medicinal plants are not those that are the easiest to acquire

The results refuted our first hypothesis. For both influenza $\left(R^{2}=0.03 ; p>0.05\right)$ and constipation $\left(R^{2}=0.13\right.$; $\mathrm{p}>0.05)$, we found a non-significant negative influence of the mean rank of perceived difficulty of acquisition on the mean rank of use (Tab. 1).

The most important medicinal plants are those that are perceived as being more efficient

Our second hypothesis was confirmed, because for both influenza $\left(R^{2}=0.40 ; p<0.05\right)$ and constipation $\left(R^{2}=0.31\right.$; $\mathrm{p}<0.05)$, we found a significant positive influence of the mean rank of perceived efficiency on the mean rank of use.

\section{The most important medicinal plants are not always those that are more palatable}

Our third hypothesis was partially confirmed. For the target influenza, we found no influence of the mean rank for perceived taste on the mean rank of use $\left(R^{2}=0.07 ; p>0.05\right)$. However, for the target constipation, we found a strong influence of this variable $\left(R^{2}=0.63 ; p<0.01\right)$.

\section{The final models}

Multiple regression for the target influenza left only the perceived efficiency as the explanatory variable. However, for the target constipation, all three variables remained in the model. However, only the perceived taste had a p-value less than 0.05 (Tab. 2).

\section{Discussion}

The lack of any influence of availability on medicinal plant use is common in ethnobotanical studies that address the apparency hypothesis. In fact, medicinal is 


\section{Carina Silva Santos, Fernanda Novais Barros, Marcelo de Paula, Juliana Rando, Viviany Teixeira do Nascimento and Patrícia Muniz de Medeiros}

Table 1. Plant species cited as being known to treat influenza and constipation in the rural community of Canabrava, Northeastern Brazil. Freq = Frequency; $\mathrm{ARu}=$ Average ranking for use; ARe = Average ranking for efficiency; ARt = Average ranking for taste; ARd $=$ Average ranking for difficulty of acquisition*.

\begin{tabular}{|c|c|c|c|c|c|c|c|}
\hline \multicolumn{8}{|c|}{ Influenza } \\
\hline Species & Vernacle & $\begin{array}{l}\text { Voucher number } \\
\text { (BRBA) }\end{array}$ & Freq (\%) & ARu & ARe & ARt & ARd \\
\hline Mentha spicata L. & Vique & 5953 & 57.1 & 1.6 & 1.5 & 1.1 & 2.7 \\
\hline Ocimum gratissium $\mathrm{L}$. & Alfavaca & 5950 & 48.6 & 1.8 & 1.6 & 1.6 & 1.3 \\
\hline Mentha pulegium L. & Puejo & ** & 42.9 & 1.9 & 2.2 & 2.0 & 2.5 \\
\hline Mentha villosa Becker & Hortelã miúdo & ** & 25.7 & 2.0 & 2.7 & 2.4 & 2.6 \\
\hline Petiveria alliacea L. & Tipi & 5954 & 22.9 & 2.4 & 1.6 & 2.6 & 1.3 \\
\hline Ocimum basilicum L. & Manjericão & 5956 & 20.0 & 2.7 & 2.9 & 2.3 & 2.1 \\
\hline Citrus limon (L.) Osbeck & Limão & 5952 & 17.1 & 2.0 & 1.7 & 1.7 & 1.7 \\
\hline Ruta graveolens $\mathrm{L}$. & Arruda & 5955 & 11.4 & 2.8 & 2.3 & 2.3 & 2.5 \\
\hline Rosmarinus officinalis L. & Alecrim & 5949 & 11.4 & 3.0 & 3.0 & 3.3 & 2.3 \\
\hline Allium sativum L. & Alho & ** & 5.7 & 2.0 & 1.5 & 3.0 & 1.0 \\
\hline Cymbopogon citratus (DC.) Stapf & Capim Santo & 5951 & 5.7 & 3.0 & 3.0 & 2.0 & 2.0 \\
\hline Sambucus nigra L. & Sabugueira & ** & 5.7 & 1.0 & 2.5 & 3.5 & 2.0 \\
\hline Plectranthus amboinicus (Lour.) Spreng. & Hortelã grosso & 5947 & 5.7 & 3.5 & 3.5 & 3.5 & 1.0 \\
\hline \multicolumn{8}{|c|}{ Constipation } \\
\hline Species & Vernacle & $\begin{array}{l}\text { Voucher number } \\
\text { (BRBA) }\end{array}$ & Freq $(\%)$ & ARu & ARe & ARt & ARd \\
\hline Amburana cearensis (Allemão) A.C. Sm. & Imburana & ** & 42.9 & 1.3 & 1.3 & 1.6 & 1.3 \\
\hline Plectranthus amboinicus (Lour.) Spreng. & Hortelã Grosso & 5947 & 20.0 & 1.3 & 1.3 & 1.14 & 1.9 \\
\hline Lippia alba (Mill.) N.E. Br. ex Britton \& P. Wilson & Erva cidreira & 5948 & 17.1 & 1.2 & 1.2 & 1.67 & 0.8 \\
\hline Allium cepa L. & Cebola & ** & 14.3 & 1.6 & 1.6 & 1.4 & 2.0 \\
\hline Unidentified 1 & Sete dor & ** & 14.3 & 1.6 & 1.6 & 1.8 & 1.6 \\
\hline Plectranthus sp. & Boldo & ** & 14.3 & 1.2 & 1.2 & 1.6 & 2.4 \\
\hline Anethum graveolens L. & Endro & ** & 8.6 & 1.3 & 1.3 & 1 & 1.3 \\
\hline Linum usitatissimum L. & Linhaça & ** & 8.6 & 1.3 & 1.3 & 1 & 2.7 \\
\hline Aloe vera (L.) Burm. f. & Babosa & 5959 & 5.7 & 2.0 & 2.0 & 2.5 & 2.0 \\
\hline Unidentified 2 & Chapadão & ** & 5.7 & 2.5 & 2.5 & 2.5 & 1.0 \\
\hline Triplaris gardneriana Wedd. & Pau-jaú & 5957 & 5.7 & 3.0 & 3.0 & 2.5 & 1.0 \\
\hline Pimpinella anisum $\mathrm{L}$. & Erva doce & ** & 5.7 & 2.0 & 2.0 & 1.5 & 2.0 \\
\hline Gymnanthemum amygdalinum (Delile) Sch. Bip. & Alumã & 5958 & 5.7 & 2.0 & 2.0 & 2 & 1.5 \\
\hline
\end{tabular}

* Difficult of acquisition refers to how hard it is to acquire a given species. For example, if the species is native and scarce in the field, or if it is exotic and difficult to buy or gather, people would indicate it has a high difficult of acquisition.

**Not collected (identified in the field)

Table 2. Regression models for variables that explain the medicinal plant prioritization for the targets 'influenza' and 'constipation' in the rural community of Canabrava, Northeastern Brazil.

\begin{tabular}{|c|c|c|}
\hline \multirow{2}{*}{$\begin{array}{c}\text { Variables in the } \\
\text { model }\end{array}$} & Influenza & Constipation \\
\hline & Efficiency* & Efficiency\#, Taste*, difficulty of acquisition\# \\
\hline AIC & 25.5 & -35.13 \\
\hline $\mathrm{R}^{2}$ & 0.40 & 0.74 \\
\hline
\end{tabular}

${ }^{*} \mathrm{p}<0.05 ; \# \mathrm{p}>0.05$

one of the use-categories with weaker relationships between availability and use according to a meta-analysis of the apparency hypothesis (Gonçalves et al. 2016).

However, despite the commonly found lack of a direct relationship between difficulty of acquisition (the opposite of availability) and use, we also believe that the profile of the cited species may have contributed to the result. Most species are exotic and acquired via trade or cultivation. Such characteristics lead to a similarity in their difficulty of acquisition (most of them are easily acquired). Therefore, when that items behave similarly are ranked, correlations may not be observed.

The maintenance of this variable in the model for the target 'constipation' also indicates that, although it does not directly influence medicinal plant prioritization, it has some degree of influence when analyzed together with other variables, such as taste and efficiency. For example, for plants with similar tastes or efficiencies, the most used may be the one that is most easily acquired. Therefore, the analysis of more targets (diseases) in future studies would help elicit the role of the 'difficulty of acquisition' in the differential use of medicinal plants.

Although there is a lack of studies assessing the perceived efficiency of medicinal plants, some investigations that investigated the association the concentration of compounds or the biological activity with the medicinal plants' importance also found strong correlations (Omar et al. 2000; Araújo et al. 2008). It is well accepted in ethnobiology 
that people are guided by, among other factors, chemical indicators (captured by taste or smell) to select plants, and experimentation by trial and error plays an important role in the formation of traditional ecological knowledge (Berkes 1993).

However, despite this acceptance, there is a lack of studies that have tried to scientifically assess that relationship, and there are problems with the methods of measuring a plant's efficiency. For example, the lack of a relationship between the concentration of a given compound (e.g., tannins) and the medicinal plants' importance does not necessarily mean that chemical efficiency is not playing a role. It is possible that other compounds that are not being measured are the bioactive agents in a given therapeutic target.

Studies have found that taste plays a significant role in medicinal plant selection. However, it seems that such a role is more related to a plant's entrance into local pharmacopoeias, initially determining whether it is employed as medicinal or not (Ankli et al. 1999; Leonti et al. 2002), and to the therapeutic targets for which the plant is used (Medeiros et al. 2015b; Gilca \& Barbulescu 2015). Our study showed that taste can also play a role in medicinal plant's importance, but that such a role may not be generalized, since it changes according to the therapeutic target being analyzed.

This result indicates that the medicinal category may not be homogeneous and that different targets may be influenced by different variables. In our case, it is possible that the importance of medicinal plants for influenza is not driven by taste because this target is more often associated with mixtures than is constipation. Although this information was not collected in our study, other investigations have shown that most mixtures are used to treat respiratory disorders (Cano \& Volpato 2004; Vandebroek et al. 2010). When a mixture is created, the taste of some less palatable plants may be camouflaged, and their undesirable characteristics may not influence selection. The differences in the variables that remained in the final models for influenza and constipation also strengthens the thesis that people may employ different criteria for choosing medicinal plants according to the therapeutic target being considered.

Our models for influenza and constipation had intermediate explanatory power (Tab. 2). None of them reached an $R^{2}$ higher than $80 \%$, possibly be due to (1) some degree of imprecision in our techniques for gathering information on perceived taste, availability, efficiency and ranking for use, since we dealt with people's memories, which can be imprecise, and (2) the influence of variables not measured by our study, such as cultural factors (e.g., local taboos). Therefore, future studies would gain explanatory power by including in the study design methods of capturing and considering cultural variables. For example, the inclusion of the frequency of a taboo positively or negatively affecting the medicinal use of a given species.

\section{Conclusions}

The joint evaluation of possible drivers of the differential use of medicinal plants showed that such a process is often multifactorial. Since we found differences in the drivers of differential use according to the therapeutic targets, we suggest that future ethnobotanical studies on medicinal plants that are looking for patterns and behaviors pay more attention to differences according to individual targets. Treating medicinal plants as a homogeneous entity may hide important particularities that may depend on the characteristic of each disease and the way people relate to such diseases.

Other factors that were not considered in our study design (e.g., cultural taboos) may also play a significant role, and we suggest future studies to include cultural variables when analyzing the differential use of medicinal plants. We also believe that other biological and ecological variables could be added to future investigations to improve the explanatory power of the models. The smell of different plants, for example, could help explain their differential use.

Finally, we recommend that future studies consider calibrating the methods for data collection and analysis. Our study chose to perform a ranking of medicinal plants according to the criteria being analyzed. However, other methods (e.g., grades instead of rankings) should be tested to observe similarities and differences in the models, as well as statistical adjustments.

\section{Acknowledgements}

The authors thank the community of Canabrava for kindly agreeing to participate in this study.

\section{References}

Albuquerque UP, Medeiros PM, Almeida ALS, et al. 2007. Medicinal plants of the caatinga (semi-arid) vegetation of NE Brazil: A quantitative approach. Journal of Ethnopharmacology 114: 325-354.

Albuquerque UP, Medeiros PM, Casas A. 2015. Evolutionary ethnobiology. New York, Springer.

Ankli A, Sticher O, Heinrich M. 1999. Yucatec Maya medicinal plants versus non medicinal plants: Indigenous characterization and selection. Human Ecology 27: 557-580.

Araújo TAS, Alencar NL, Amorim ELC, Albuquerque UP. 2008. A new approach to study medicinal plants with tannins and flavonoids contents from the local knowledge. Journal of Ethnopharmacology 120: 72-80.

Berkes F. 1993. Traditional ecological knowledge in perspective. In: Inglis JT. (ed.) Traditional ecological knowledge: Concepts and cases. Ottawa, Canadian Museum of Nature and the International Development Research Centre. p. 1-9.

Cano JH, Volpato G. 2004. Herbal mixtures in the traditional medicine of Eastern Cuba. Journal of Ethnopharmacology 90: 293-316.

Gilca M, Barbulescu A. 2015. Taste of medicinal plants: A potential tool in predicting ethnopharmacological activities? Journal of Ethnopharmacology 174: 464-473. 


\section{Carina Silva Santos, Fernanda Novais Barros, Marcelo de Paula, Juliana Rando, Viviany Teixeira do Nascimento and Patrícia Muniz de Medeiros}

Gonçalves PHS, Albuquerque UP, Medeiros PM. 2016. The most commonly available woody plant species are the most useful for human populations: A meta-analysis. Ecological Applications 26: 22382253.

Khafagi IK, Dewedar A. 2000. The efficiency of random versus ethnodirected research in the evaluation of Sinai medicinal plants for bioactive compounds. Journal of Ethnopharmacology 71: 365-376.

Leonti M, Sticher O, Heinrich M. 2002. Medicinal plants of the Popoluca, México: organoleptic properties as indigenous selection criteria. Journal of Ethnopharmacology 81: 307-315.

Lucena RFP, Araújo EL, Albuquerque UP. 2007. Does the local availability of woody caatinga plants (Northeastern Brazil) explain their use value? Economic Botany 61: 347-361.

Lucena RFP, Medeiros PM, Araújo EL, Alves AGC, Albuquerque UP. 2012. The ecological apparency hypothesis and the importance of useful plants in rural communities from Northeastern Brazil: An assessment based on use value. Journal of Environmental Management 96: 106115.

Medeiros PM, Ladio AH, Albuquerque UP. 2015a. Local criteria for medicinal plant selection. In: Albuquerque UP, Medeiros PM, Casas A. (eds.) Evolutionary ethnobiology. New York, Springer. p. 149-162.

Medeiros PM, Pinto BLS, Nascimento VT. 2015b. Can organoleptic properties explain the differential use of medicinal plants? Evidence from Northeastern Brazil. Journal of Ethnopharmacology 159: 43-48.

Molares S, Ladio A. 2009. Chemosensory perception and medicinal plants for digestive ailments in a Mapuche community in NW Patagonia, Argentina. Journal of Ethnopharmacology 123: 397-406.

Mollik AH, Hossan S, Paul AK, Taufi q-Ur-Rahman M, Jahan R, Rahmatullah M. 2010. A comparative analysis of medicinal plants used by folk medicinal healers in three districts of Bangladesh and Inquiry as to mode of selection of medicinal plants. Ethnobotany Research and Applications 8: 195-218

Omar S, Lemmonier B, Jones N, et al. 2000. Antimicrobial activity of extracts of eastern North American hardwood trees and relation to traditional medicine. Journal of Ethnopharmacology 73: 161 -170.

Rodrigues E, Carlini EA. 2006. A comparison of plants utilized in ritual healing by two Brazilian cultures: Quilombolas and Kraho Indians. Journal of Psychoactive Drugs 38: 285-295.

Slish DF, Ueda H, Arvigo R, Balick MJ. 1999. Ethnobotany in the search for vasoactive herbal medicines. Journal of Ethnopharmacology 66: 159-165.

Vandebroek I, Balick M, Ososki A, et al. 2010. The importance of botellas and other plant mixtures in Dominican traditional medicine. Journal of Ethnopharmacology 128: 20-41. 